TẠP CHÍ KHOA HỌC ĐẠI HỌC ĐÀ LẠT Tập 6, Số 1, 2016 129-139

\title{
PHÂN TÍCH SWOT VỀ TIỀM NĂNG DU LICCH VÙNG DUYÊN HẢI NAM TRUNG BỘ
}

\author{
Nguyễn Thị Thanh Ngân ${ }^{a^{*}}$
}

${ }^{a}$ Khoa Quản trị Du lịch, Trường Đại học Đà Lạt, Lâm Đồng, Việt Nam

Nhận ngày 17 tháng 01 năm 2016

Chỉnh sửa ngày 29 tháng 03 năm 2016 | Chấp nhận đăng ngày 29 tháng 03 năm 2016

\section{Tóm tắt}

Vùng Duyên hải Nam Trung Bộ có tiềm năng du lịch rất đa dạng và phong phú. Tiềm năng du lịch là điều kiện co bản của sụ phát triển du lịch. Bài báo này sủ dụng kỹ thuật phân tích SWOT để xác định điểm mạnh, điểm yếu, cơ hội và thách thức về tiềm năng du lịch vùng Duyên hải Nam Trung Bộ. Nhũng nhân tố cu thể về tiềm năng du lịch của vùng đã được xác định, tổng hợp và kết quả nghiên cứu được đề nghị cho nghiên cứu tiếp theo.

Từ khóa: Ma trận SWOT; Sức hấp dẫn du lịch; Tiềm năng du lịch; Vùng Duyên hải Nam Trung Bộ.

\section{GIỚI THIỆ}

Vùng Duyên hải Nam Trung bộ bao gồm thành phố Đà Nẵng và bảy tỉnh: Quảng Nam, Quảng Ngãi, Bình Định, Phú Yên, Ninh Thuận, Khánh Hòa và Bình Thuận với diện tích tự nhiên $44.376,9 \mathrm{~km}^{2}$ và bờ biển dài gần $1.200 \mathrm{~km}^{2}$. Với vị trí địa lý tiếp giáp vùng Bắc Trung bộ ở phía Bắc, vùng Tây Nguyên ở phía Tây, Cộng hòa Dân chủ Nhân dân Lào ở Tây Bắc, vùng Đông Nam Bộ ở phía Tây Nam, phía Đông là biển Đông là điều kiện rất thuận lợi cho phát triển du lịch. Hơn nữa, vùng Duyên hải Nam Trung Bộ nằm trên tuyến du lịch xuyên Việt, là cầu nối du lịch Bắc - Nam; điểm đầu của các tuyến du lịch "Con đường Di sản Miền Trung”, "Con đường xanh Tây Nguyên"; cửa ngõ vùng Tây Nguyên; đầu cầu và cũng là cửa ngõ ra biển Đông của hành lang du lịch Đông - Tây. Với vị trí thuận lợi đó, vùng Duyên hải Nam Trung bộ có tiềm năng cao trong liên kết phát triển du lịch của vùng. Nhiệt độ trung bình năm từ

\footnotetext{
* Tác giả liên hệ: Email: nganntt@dlu.edu.vn

${ }^{1,2}$ Số liệu thống kê trong Quy hoạch tổng thể phát triển du lịch vùng Duyên hải Nam Trung bộ đến năm 2020, tầm nhìn 2030.
} 
$25^{\circ} \mathrm{C}$ đến $26^{\circ} \mathrm{C}$, trung bình năm cao nhất $29^{\circ} \mathrm{C}$ đến $31^{\circ} \mathrm{C}$, trung bình năm thấp nhất $21^{\circ} \mathrm{C}$ đến $23^{\circ} \mathrm{C}$. Mỗi năm có 2 mùa rõ rệt: mùa khô kéo dài từ tháng 1 đến tháng 8 và mùa mưa từ tháng 9 đến tháng 12 , tuy nhiên đây cũng là vùng chịu ảnh hưởng nặng nề của thiên tai và biến đổi khí hậu. Đây là yếu tố bất lợi lớn của vùng trong khai thác phát triển du lịch.

Về tài nguyên du lịch tự nhiên, vùng có nhiều bãi biển đẹp nổi tiếng như: Non Nước (Đà Nẵng), Cửa Đại (Quảng Nam), Sa Huỳnh (Quảng Ngãi), Quy Nhơn (Bình Định), Tuy Hòa (Phú Yên), Vân Phong - Đại Lãnh (Nha Trang), Ninh Chữ (Ninh Thuận), Mũi Né (Bình Thuận), vịnh Lăng Cô và vịnh Nha Trang nằm trong danh mục những vịnh biển đẹp nhất thế giới; quần đảo và đảo có giá trị du lịch cao như: Cù Lao Chàm (Quảng Nam), Lý Sơn (Quảng Ngãi), Hòn Mun, Hòn Tre, Hòn Tằm (Khánh Hòa), Phú Quý (Bình Thuận), dải Trường Sơn chạy dọc ở phía tây tạo ra địa hình rừng núi cheo leo, nhiều thác, ghềnh và những khu rừng nguyên sinh với thảm thực vật và hệ động vật phong phú. Vùng Duyên hải Nam Trung bộ còn có hệ thống tài nguyên du lịch nhân văn rất phong phú và đặc sắc, như hai di sản văn hóa thế giới gồm đô thị cổ Hội An và Thánh địa Mỹ Sơn (Quảng Nam), nhiều di tích lịch sử, di tích kiến trúc nghệ thuật, di tích tôn giáo tín ngưỡng, địa điểm khảo cổ, danh lam thắng cảnh...của các thời kỳ: tiền - sơ sử (với hai nền văn hóa khảo cổ là văn hóa Sa Huỳnh và văn hóa Đông Sơn), trung đại (các di tích thời Champa và thời Đại Việt), cận đại (các di tích thời chúa Nguyễn, thời Tây Sơn và thời Nguyễn), hiện đại (các di tích thời chống Pháp và chống Mỹ), kho tàng di sản văn hóa phi vật thể giàu bản sắc của hàng chục cộng đồng tộc người bản địa và lưu dân cư trú, sinh tụ trên vùng đất này hàng ngàn năm qua (Trần Đức Anh Sơn, 2013). Ngoài các giá trị trên, vùng còn chứa đựng nhiều tài nguyên du lịch rất có giá trị cho hoạt động du lịch như phong tục, tập quán, lễ hội (lễ hội pháo hoa quốc tế tại Đà Nẵng, lễ hội đêm rằm phố cổ tại Quảng Nam, lễ khao lề thế lính Hoàng Sa tại Quảng Ngãi, Festival võ cổ truyền tại Bình Định, lễ hội đâm trâu tại Phú Yên, Festival biển tại Nha Trang, lễ hội Kate tại Ninh Thuận, lễ hội rước đèn Trung Thu tại Bình Thuận), ẩm thực, nghề truyền thống rất được du khách quan tâm tìm hiểu. Ngoài các yếu tố trên, vùng Duyên hải Nam Trung bộ còn có hệ thống cơ sở vật chất kỹ thuật và cơ sở hạ tầng không ngừng được đầu tư nâng cấp. Hệ thống giao thông hội tụ đầy đủ các loại như đường bộ (quốc lộ $1 \mathrm{~A}$, quốc lộ $14, \ldots$ ), đường thủy (sông và biển), đường 
sắt và đường hàng không (sân bay quốc tế Đà Nẵng, Cam Ranh ở Khánh Hòa, Chu Lai ở Quảng Nam, Phù Cát ở Bình Định, Tuy Hòa ở Phú Yên), thuận lợi cho việc liên kết phát triển du lịch. Hệ thống cơ chế chính sách không ngừng được hoàn thiện nhằm thúc đẩy phát triển du lịch của vùng. Vấn đề khai thác tiềm năng du lịch hiệu quả và phát triền du lịch bền vững trong vùng đang được chú trọng trong định hướng phát triển $\mathrm{du}$ lịch của mỗi địa phương và quy hoạch du lịch của vùng.

\section{TỔNG QUAN NGHIÊN CÚU}

\subsection{Tiềm năng du lịch và sức hấp dẫn du lịch}

Sau năm 1990, thuật ngữ tiềm năng du lịch bắt đầu được đề cập trong lĩnh vực địa lý và kinh tế, tuy nhiên khi nghiên cứu về tiềm năng du lịch có nhiều quan điểm khác nhau (Iatu và Bulai, 2011). Hall và Page (2004) cho rằng tiềm năng du lịch là điều kiện co bản của sự phát triển. Cho đến nay, thuật ngữ tiềm năng du lịch được sử dụng khá rộng rãi trong cả nghiên cứu lý thuyết và thực tiễn. Tại Việt Nam, thuật ngữ tiềm năng du lịch được sử dụng khá phổ biến, đặc biệt trong các văn bản Quy hoạch du lịch. Nguyễn Minh Tuệ (2011) đã đề cập đến tiềm năng phát triển du lịch và cho rằng tiềm năng phát triển du lịch bao gồm vị trí địa lý, tài nguyên du lịch và cơ sở hạ tầng. Quan điểm này gần giống với nghiên cứu của các tác giả Iatu và Bulai (2011); Ion và cộng sự (2011) về tiềm năng du lịch. Trong khi Iatu và Bulai (2011) định nghĩa tiềm năng du lịch bao gồm tài nguyên tự nhiên, tài nguyên văn hóa, cơ sở hạ tầng du lịch và cơ sở hạ tầng chung thì Ion và cộng sự (2011) cho rằng tiềm năng du lịch bao gồm tiềm năng du lịch tự nhiên, tiềm năng nhân văn và cơ sở hạ tầng du lịch và cơ sở hạ tầng kỹ thuật. Thêm vào đó, có tác giả cho rằng tiềm năng du lịch là tất cả các nguồn tài nguyên tự nhiên và tài nguyên nhân văn (Ielenicz và Comănescu, 2006). Tác giả này cũng đề xuất một mô hình nghiên cứu về tiềm năng du lịch $T P=T a+A i+N i+D i+S i$ trong đó các yếu tố được giải thích như sau: $T a$ là sức hấp dẫn du lịch, $A i$ là chỉ số tỷ lệ hấp dẫn, $N i$ là chỉ số chất lượng mạng lưới, $D i$ là chỉ số khoảng cách và $S i$ là chỉ số chất lượng dịch vụ. Quan điểm này đã có sự khác biệt so với nhận thức trước đây cho rằng tiềm năng du lịch chỉ bao gồm tài nguyên du lịch tự nhiên và nhân văn (trích từ Iatu và Bulai, 2011). Chương trình Leader European Observatory (2005) đã đề cập đến đánh giá tiềm năng 
du lịch nông thôn và định nghĩa tiềm năng du lịch là mối quan hệ giũu cung-cầu; xu huớng thị truờng và năng lục cạnh tranh; trong khi đó cung du lịch lại bao gồm các nhân tố về tự nhiên, văn hóa, kinh tế-xã hội, cơ sở hạ tầng và các dịch vụ. Hơn nữa, chương trình này cũng nhấn mạnh vào hai nội dung chính để đánh giá tiềm năng du lịch bao gồm: 1) Phân tích các điều kiện hiện tại như cung-cầu, năng lực cạnh tranh và xu hướng thị trường, 2) Xác định những điểm mạnh, điểm yếu, cơ hội và thách thức để xác định các phương án phát triển du lịch. Mamun và Mitra (2012) khi đánh giá về tiềm năng du lịch ở quận Murshidabad District, phía tây Bengal, Ân Độ đã chỉ ra tiềm năng du lịch bao gồm các yếu tố vật lý (khả năng tiếp cận, hệ thống cơ sở lưu trú, thông tin du lịch, hàng lưu niệm, hệ thống viễn thông, ẩm thực, bãi đỗ xe, phương tiện giải trí); yếu tố xã hội (hội chợ, thời gian tham quan, thời gian lưu trú, khả năng tương thích với các điểm lân cận, an ninh an toàn, tệ nạn xã hội, hành vi nhà khai thác du lịch) và yếu tố môi trường (thiên tai, ô nhiễm môi trường đất, nước, không khí). Như vậy, với các cách tiếp cận và bối cảnh khác nhau thì cách hiểu về tiềm năng du lịch cũng có sự khác nhau và tiềm năng du lịch là một khái niệm bao hàm cả tài nguyên du lịch. Tiềm năng du lịch là khả năng của một vùng để thu hút khách du lịch. Trong trường hợp một vùng có tiềm năng du lịch hạn chế thì rất khó để phát triển du lịch thành công.

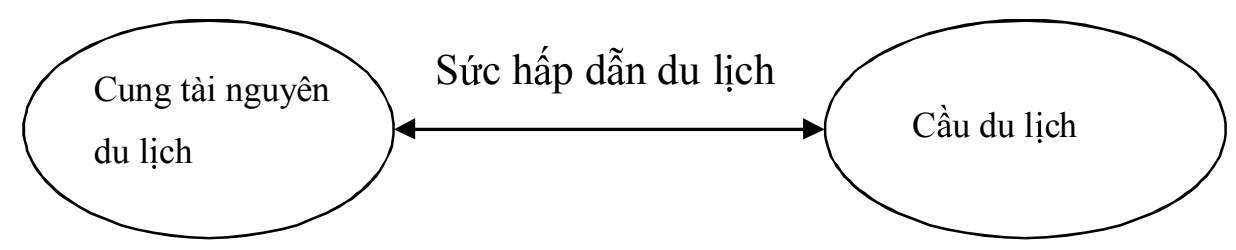

\section{Hình 1. Sức hấp dẫn du lịch thể hiện sự tương tác cung - cầu}

Nguồn: Iatu và Bulai, 2011

Nếu như tiềm năng du lịch thường được các tác giả nghiên cứu tiếp cận dưới góc độ cung du lịch thì sức hấp dẫn du lịch lại tiếp cận dưới góc độ sự tương tác giữa cung và cầu du lịch. Formica (2000) chỉ ra rằng thuật ngữ "tiềm năng" có thể được thay thế bằng "sức hấp dẫn" trong đó chỉ rõ mối quan hệ giữa cung và cầu du lịch. Sức hấp dẫn 
du lịch là bất kỳ một đối tượng, người, địa điểm có khả năng thu hút khách du lịch theo vùng địa lý hoặc thông qua các kênh phân phối (Stange và cộng sự, 2005).

Khi nghiên cứu về sức hấp dẫn du lịch của du lịch cuối tuần tại Hà Nội có tác giả đã chỉ ra sức hấp dẫn du lịch bao gồm tài nguyên du lịch, tính đa dạng độc đáo của các hoạt động du lịch, thời gian hoạt động, sức chứa du lịch, cơ sở hạ tầng và cơ sở vật chất kỹ thuật, mức độ khai thác tài nguyên (Nguyễn Thị Hải, 2003). Để đánh giá tiềm năng du lịch của một vùng, địa phương cần phải xác định được các yếu tố của tiềm năng du lịch và cũng cần phải đánh giá thêm sức hấp dẫn về tiềm năng du lịch của vùng để làm cơ sở cho việc phát triển du lịch của vùng.

\subsection{Ma trận SWOT (Ma trận điểm mạnh, điểm yếu, cơ hội và thách thức)}

Ma trận SWOT là tập hợp viết tắt những chữ cái đầu tiên của các từ Tiếng Anh: Strengths (điểm mạnh), Weaknesses (điểm yếu), Opportunities (cơ hội), Threats (đe dọa hay thách thức). Ban đầu ma trận SWOT được sử dụng để phân tích tính hình kinh doanh của doanh nghiệp vào những năm 60,70 của thế kỷ $\mathrm{XX}$ và để tìm ra giải pháp giúp các nhà lãnh đạo đồng thuận và tiếp tục thực hiện việc hoạch định chiến lược (Valentin, 2005). Cho đến nay, ma trận SWOT đã được sử dụng rộng rãi không chỉ trong phạm vi doanh nghiệp mà còn mở rộng trong các ngành, các lĩnh vực kinh tế, các địa phương, các vùng, quốc gia. Ma trận SWOT mang lại một cách nhìn toàn diện về các vấn đề của kinh tế để từ đó các nhà quản lý, nhà hoạch định chính sách có thể sử dụng làm căn cứ cho những quyết định mang tính chiến lược. Phân tích SWOT là việc đánh giá một cách chủ quan các dữ liệu bao gồm các yếu tố bên trong (điểm mạnh, điểm yếu) và các yếu tố bên ngoài (cơ hội, thách thức). Ma trận SWOT được trình bày dưới dạng một ma trận 2 hàng 2 cột, chia làm 4 phần: $\mathrm{S}-\mathrm{W}$ (yếu tố bên trong) và $\mathrm{O}-\mathrm{T}$ (yếu tố bên ngoài). Sự kết hợp của các yếu tố $\mathrm{SO}, \mathrm{ST}$, WO, WT có ý nghĩa quan trọng đối với việc đề ra các phương án chiến lược . 


\begin{tabular}{|c|c|c|}
\hline Các yếu tố bên trong & Điểm mạnh (S) & Điểm yếu (W) \\
\hline Các yếu tố bên ngoà̀ & & WO \\
\hline Cơ hội $(\mathrm{O})$ & SO & WT \\
\hline Thách thức $(\mathrm{T})$ & ST & \\
\hline
\end{tabular}

\section{Hình 2. Ma trận SWOT}

\subsection{Mục tiêu nghiên cứu}

Thông qua việc làm rõ bản chất tiềm năng du lịch kết hợp ma trận SWOT xác định và tổng hợp các nhân tố bên trong (điểm mạnh, điểm yếu) và bên ngoài (cơ hội, thách thức) về các yếu tố tiềm năng du lịch và các điều kiện cơ bản của vùng làm cơ sở để nghiên cứu đánh giá thực trạng khai thác phát triển du lịch vùng Duyên hải Nam Trung bộ.

\subsection{Phương pháp nghiên cứu}

Bài báo sử dụng phương pháp khảo sát chuyên gia để đánh giá tiềm năng để phát triển du lịch của vùng. Chuyên gia được lựa chọn từ các nhà quản lý du lịch địa phương của 8 tỉnh trong vùng Duyên hải Nam Trung bộ và các giảng viên giảng dạy về du lịch (có trên 5 năm kinh nghiệm) để đánh giá tiềm năng du lịch của vùng. Tổng số chuyên gia tham gia khảo sát là 39 người. Phiếu khảo sát được trực tiếp gửi đến các chuyên gia du lịch. Nội dung chính của cuộc khảo sát tập trung vào xác định các yếu tố tiềm năng du lịch, sức hấp dẫn du lịch và các điều kiện để phát triển du lịch của vùng. Thêm vào đó, dựa trên việc nghiên cứu các nguồn tài liệu về vùng qua tạp chí chuyên ngành, sách báo, các phương tiện thông tin đại chúng để có cơ sở khẳng định các nhân tố thuộc ma trận SWOT. Trên cơ sở đó nhận diện những điểm mạnh, điểm yếu, cơ hội và thách thức để làm cơ sở cho việc khai thác tài nguyên du lịch của vùng.

\subsection{Kết quả nghiên cứu}

Thông qua việc tổng hợp phiếu khảo sát chuyên gia đánh giá về tiềm năng du lịch của vùng Duyên hải Nam Trung bộ kết hợp với nghiên cứu tổng quan tài liệu về 
tiềm năng du lịch, cơ hội và thách thức của vùng được tổng hợp và trình bày cụ thể ở bảng sau:

Bảng 1. Những cơ hội và thách thức của vùng Duyên hải Nam Trung bộ

\begin{tabular}{|c|c|}
\hline Co' hội (Opportunities) & Thách thức (Threats) \\
\hline $\begin{array}{l}\text { 1. Một số địa phương phát triển du lịch đã } \\
\text { có hình ảnh, thương hiệu như Đà Năng, } \\
\text { Quảng Nam, Khánh Hòa, Bình Thuận. } \\
\text { 2. Vùng có sức hấp dẫn du lịch về tài } \\
\text { nguyên du lịch tương đối cao. } \\
\text { 3. Chính sách hội nhập quốc tế của Việt } \\
\text { Nam (tham gia Hiệp định đối tác xuyên } \\
\text { Thái Bình Dương TPP, Cộng đồng kinh tế } \\
\text { các nước ASEAN vào năm 2015) tạo điều } \\
\text { kiện thuận lợi cho việc phát triển du lịch } \\
\text { vùng. } \\
\text { 4. Chỉ dẫn định hướng khai thác tài nguyên } \\
\text { du lịch của vùng thể hiện trong Quy hoạch } \\
\text { phát triển du lịch vùng Duyên hải Nam } \\
\text { Trung Bộ đến năm } 2020 \text {, tầm nhìn } 2030 \text {. }\end{array}$ & $\begin{array}{l}\text { 1. Vấn đề cạnh tranh giữa các địa phương } \\
\text { trong vùng và giữa các vùng trong cả } \\
\text { nước } \\
\text { 2. Thiên tai và biến đổi khí hậu có ảnh } \\
\text { hưởng nghiêm trọng đến vùng (bão, hạn } \\
\text { hán, lũ lụt...) } \\
\text { 3. Nhu cầu du lịch thế giới có nhiều thay } \\
\text { đổi, đặc biệt xu hướng du lịch trong những } \\
\text { năm gần hướng đến du lịch du lịch dựa } \\
\text { vào cộng đồng, du lịch sinh thái, du lịch } \\
\text { thiên nhiên, du lịch văn hóa và du lịch bền } \\
\text { vững. } \\
\text { 4. Khai thác tài nguyên du lịch gắn với } \\
\text { phát triển bền vững. }\end{array}$ \\
\hline
\end{tabular}

Việc xác định những nhân tố bên trong được xem như xác định những tiềm năng du lịch quan trọng cho việc phát triển du lịch của vùng. Bảng 2 thể hiện các nhân tố thuận lợi và khó khăn của vùng như Bảng 2

Bảng 2. Những thuận lọ̣i và khó khăn của vùng Duyên hải Nam Trung Bộ

\begin{tabular}{|c|c|}
\hline Đie & Đle \\
\hline 1. Vùng có & h khôr \\
\hline 2. Khả năng & đa dạng \\
\hline tuyế & của c \\
\hline 14), hệ thốn & 2. $\mathrm{Co}$ \\
\hline đưò & đặc bi \\
\hline di & điểm du lịch \\
\hline nách kl & 3. Hệ thống cơ sở vật chất kỹ thuật chưa \\
\hline
\end{tabular}




\begin{tabular}{|c|c|}
\hline $\begin{array}{l}\text { 3. Hệ thống tài nguyên du lịch tự nhiên đa } \\
\text { dạng, đặc biệt tài nguyên du lịch biển đảo, } \\
\text { tài nguyên di sản. } \\
\text { 4. Hệ thống tài nguyên du lịch nhân văn } \\
\text { rất phong phú và đặc sắc như tài nguyên di } \\
\text { sản văn hóa Thế giới, hệ thống tháp Chăm, } \\
\text { lễ hội, sự kiện du lịch,... } \\
\text { 5. Các chính sách phát triển du lịch được } \\
\text { chú trọng tại các địa phương } \\
\text { 6. An ninh, an toàn }\end{array}$ & $\begin{array}{l}\text { đồng bộ. } \\
\text { 4. Công tác quảng bá hình ảnh du lịch của } \\
\text { vùng hạn chế. } \\
\text { 5. Chất lượng nguồn nhân lực chưa đáp } \\
\text { ứng tốt được nhu cầu phát triến du lịch } \\
\text { 6. Khó khăn trong liên kết phát triển du } \\
\text { lịch nội vùng, liên vùng và hợp tác các bên } \\
\text { liên quan phát triển đặc biệt liên kết, hợp } \\
\text { tác phát triển bền vững nội vùng. }\end{array}$ \\
\hline
\end{tabular}

Ma trận SWOT là việc kết hợp các nhân tố bên trong và bên ngoài như SO, WO, ST và WT để đề ra các phương án chiến lược. Đây cũng chính là những định hướng quan trọng trong việc khai thác tài nguyên du lịch cho vùng một cách hiệu quả. Do đó, dựa trên các nhân tố điểm mạnh, điểm yếu, cơ hội và thách thức ở trên, bài báo này đề xuất một vài phương án chiến lược cho việc khai thác tài nguyên du lịch của vùng Duyên hải Nam Trung bộ như sau:

Khai thác thế mạnh tài nguyên du lịch của từng địa phương trong vùng. Xác định các sản phẩm du lịch chủ lực của từng địa phương, trên cơ sở đó xác định sản phẩm đặc trưng của từng địa phương như du lịch biển đảo; du lịch di sản đồng thời đa dạng hóa các sản phẩm du lịch dựa trên thế mạnh tài nguyên của vùng như du lịch sinh thái dựa vào cộng đồng, du lịch nghỉ dưỡng, du lịch nông nghiệp, du lịch văn hóa, du lịch thể thao mạo hiểm..., xây dựng hình ảnh du lịch đặc trưng đại diện chung cho vùng.

Định hướng các tuyến du lịch chủ đạo và các tuyến du lịch chuyên biệt. Chú trọng đa dạng tuyến du lịch giữa các địa phương trong vùng và các địa phương vùng khác trên cơ sở liên kết khai thác các tài nguyên du lịch giữa các vùng để tạo ra sự liên hoàn, đa dạng về sản phẩm du lịch.

Thúc đẩy quá trình liên kết phát triển vùng như liên kết trong thực hiện đồng bộ về cơ sở hạ tầng giao thông đường bộ, liên kết sản phẩm du lịch để tạo ra thế liên hoàn, sức hấp dẫn riêng có cho vùng. Liên kết trong hoạch định chính sách phát triển du lịch 
trong vùng. Liên kết trong đào tạo nâng cao chất lượng nguồn nhân lực và quảng bá du lịch vùng. Việc liên kết cần thực hiện trong phạm vi nội vùng và liên vùng.

Hợp tác các bên liên quan trong phát triển du lịch vùng bền vững. Phát triển bền vững đang là một thách thức lớn đối với sự phát triển của vùng Duyên hải Nam Trung Bộ. Thiên tai và biến đổi khí hậu cũng tác động rất rõ nét đến Vùng Duyên hải Nam Trung Bộ. Do đó nếu chỉ đơn thuần một chủ thể tham gia vào phát triển du lịch bền vững thì không thể giải quyết được vấn đề phát triển du lịch về lâu dài. Do đó, việc hợp tác các bên liên quan bao gồm Chính quyền, các cơ quan quản lý du lịch, các tổ chức du lịch, hiệp hội du lịch, doanh nghiệp du lịch, khách du lịch và cộng đồng dân cư cùng tham gia vì mục tiêu phát triển bền vững thì mới có thể đạt được hiệu quả bền vững lâu dài. Tuy nhiên, hợp tác nên thiết lập ở nhiều mức độ khác nhau như hợp tác trong từng địa phương hoặc hợp tác trong vùng, hợp tác với các địa phương khác hoặc vùng khác để mở ra nhiều cơ hội tốt cho việc khai thác tài nguyên du lịch của vùng hiệu quả. Hợp tác các bên liên quan trong hoạch định điểm đến.

\section{KẾT LUẬn VÀ HÀM Ý NGHIÊN CÚU}

Vùng Duyên hải Nam Trung Bộ có hệ thống tài nguyên du lịch rất đa dạng và đặc sắc. Tuy nhiên, nếu chỉ xem xét hệ thống thống tài nguyên du lịch của vùng thì chưa đủ yếu tố cấu thành nên sản phẩm du lịch và việc khai thác phát triển du lịch sẽ gặp rất nhiều khó khăn, thách thức. Do đó, việc phân tích các yếu tố cơ hội, thách thức, điểm mạnh, điểm yếu và là cơ sở quan trọng định hướng cho việc khai thác tài nguyên du lịch của vùng, đặc biệt định hướng khai thác tài nguyên du lịch theo hướng bền vững. Kết quả nghiên cứu đã chỉ ra có 4 yếu tố cơ hội, 4 yếu tố thách thức, 6 điểm mạnh và 6 điểm yếu. Dựa trên kết quả này, cần có nghiên cứu tiếp theo về thực trạng khai thác tài nguyên du lịch của vùng Duyên hải Nam Trung bộ để đánh giá được đầy đủ tiềm năng cũng như thực trạng khai thác tài nguyên du lịch của vùng hiện nay. 


\section{TÀI LIỆU THAM KHẢO}

[1] Nguyễn Thị Hải, Xác định lục hấp dẫn du lịch tại một số điểm du lịch cuối tuần của Hà Nội. Tạp chí khoa học Đại học Quốc gia Hà Nội, KH \& TN T XIX. số 4, trang 22-27, 2003. Nguồn http://repository.vnu.edu.vn/handle/11126/6358

[2] Nguyễn Minh Tuệ chủ biên, Địa lý du lịch Việt Nam, trang 119-158, Nhà xuất bản Giáo dục Việt Nam, tái bản lần thứ nhất, 2011.

[3] Trần Đức Anh Sơn, Khai thác di sản văn hóa phi vật thể ở các tỉnh Duyên hải miền Trung để phát triến du lịch. Kỷ yếu hội thảo Phát triển sản phẩm du lịch vùng Duyên hải Miền Trung, Khánh Hòa tháng 6 năm 2013.

[4] Hall, C.M., Page, S.J. The Geography of Tourism and Recreation, Routledge, New York, 2004

[5] Formica, S. Destination attractiveness as a function of supply and demand interaction. PhD Dissertation, Virginia Polytechnic Institute and State University, 2000.

[6] Mamun, A.A., Mitra, S. A Methodology for Assessing Tourism Potential: Case Study Murshidabad District, West Bengal, India. International Journal of Scientific and Research Publications, Volume 2, Issue 9, September, 2012.

[7] Ciurea, I.V., Mihalache, R., Ungureanu, G., Brezuleanu, S. Studies Regarding the Evaluation of the Tourist Potential of Oituz Hydrographical Basin-Bacau County, Bulletin UASVM Horticulture, 68(2), Print ISSN 1843-5254; Electronic ISSN 1843-5394, pp-49-54, 2011.

[8] Valentin, E.K. Away With SWOT Analysis: Use Defensive/Offensive Evaluation Instead, The Journal of Applied Business Research - Spring Volume 21, Number 2, Page 91-105, 2005.

[9] LEADER European Observatory Programme (2005). Evaluating a territory's tourism potential, 2005. 


\title{
SWOT ANALYSIS OF TOURISM POTENTIAL IN THE SOUTHERN CENTRAL REGION
}

\author{
Nguyen Thi Thanh Ngan ${ }^{\mathrm{a}^{*}}$ \\ ${ }^{a}$ The Faculty of Tourism Management, Dalat University, Lamdong, Vietnam \\ *Corresponding author: nganntt@dlu.edu.vn \\ Article history \\ Received: January $17^{\text {th }}, 2016$ \\ Received in revised form: March $29^{\text {th }}, 2016$ \\ Accepted: March $29^{\text {th }}, 2016$
}

\begin{abstract}
The Southern Central region has notable tourism potential. Tourism potential is the basic condition for tourism development. This paper uses techniques for SWOT analysis to identify strengths, weaknesses of tourism potential in the Southern Central region and opportunities and challenges to cope with. The specific elements of the tourism potential of the region have been identified, and the results of the study are recommended for further studies.
\end{abstract}

Key words: Attractiveness; SWOT analysis; Tourism potential; The Southern Central region. 